The Journal of $\mathbf{N}_{\text {onlinear }} \mathbf{S}$ cience and Applications http://www.tjnsa.com

\title{
ON KANNAN FIXED POINT PRINCIPLE IN GENERALIZED METRIC SPACES
}

\author{
DOREL MIHEŢ ${ }^{1}$
}

\begin{abstract}
The concept of a generalized metric space, where the triangle inequality has been replaced by a more general one involving four points, has been recently introduced by Branciari. Subsequently, some classical metric fixed point theorems have been transferred to such a space. The aim of this note is to show that Kannan's fixed point theorem in a generalized metric space is a consequence of the Banach contraction principle in a metric space.
\end{abstract}

\section{INTRODUCTION AND PRELIMINARIES}

The following notion of generalized metric space has been introduced by Branciari in [3]:

Definition 1.1. ([3]) Let $X$ be a set and $d: X^{2} \longrightarrow \mathbb{R}$ be a mapping. The pair $(X, d)$ is called a generalized metric space (in the sense of Branciari) if, for all $x, y \in X$ and for all distinct points $z, w \in X$, each of them different from $x$ and $y$, one has

(i) $d(x, y)=0$ if and only if $x=y$,

(ii) $d(x, y)=d(y, x)$,

(iii) $d(x, y) \leq d(z, z)+d(z, w)+d(w, y)$.

Any metric space is a generalized metric space, but the converse is not true ([3]). A generalized metric space is a topological space with neighborhood basis given by

$$
\mathcal{B}=\{B(x, r), x \in X, r>0\}
$$

where $B(x, r)=\{y \in X, d(x, y)<r\}$.

Date: Received: 2 November 2008; Revised: 18 March 2009.

* Corresponding author.

2000 Mathematics Subject Classification. 47H10; 54H25.

Key words and phrases. Generalized metric space; T-orbitally complete; Fixed point. 
Let $(X, d)$ be a generalized metric space. A sequence $\left\{x_{n}\right\}$ in $X$ is said to be Cauchy if for any $\epsilon>0$ there exists $n_{\epsilon} \in \mathbb{N}$ such that for all $m, n \in \mathbb{N}, n \geq n_{\epsilon}$ one has $d\left(x_{n}, x_{n+m}\right)<\epsilon$. The space $(X, d)$ is called complete if every Cauchy sequence in $X$ is convergent in $X$. Let $T: X \rightarrow X$ be a mapping. The space $(X, d)$ is said to be $T$-orbitally complete if every Cauchy sequence which is contained in $O(x, \infty):=\left\{T^{n} x, n \in \mathbb{N} \cup\{0\}\right\}$ for some $x \in X$, converges in $X$.

Starting with the paper of Branciari [3, some classical metric fixed point theorems have been transferred to generalized metric spaces, see e.g., [2], [1], 6], [5], [7. Following an idea in [9], in this short note we show that Kannan's fixed point theorem [8] in such a space is a consequence of the following Banach contraction principle in a metric space:

Theorem 1.2. ([4]) Let $(X, \rho)$ be a metric space and $T: X \rightarrow X$ be a mapping such that

$$
\rho(T x, T y) \leq q \rho(x, y) \forall x, y \in X
$$

where $0 \leq q<1$. If $X$ is T-orbitally complete then $T$ has a unique fixed point in $X$.

\section{MAIN RESUlts}

We begin by recalling the fixed point theorem of Kannan in a generalized metric space, as stated in [5].

Theorem 2.1. (Kannan fixed point principle in a generalized metric space) Let $(X, d)$ be a generalized metric space and $T: X \rightarrow X$ be a mapping such that

$$
(K) d(T x, T y) \leq \beta[d(x, T x)+d(y, T y)] \quad(x, y \in X)
$$

where $0<\beta<\frac{1}{2}$. If $X$ is T-orbitally complete then $T$ has a unique fixed point in $X$.

We note that the fact that $T$ has at most one fixed point easily follows from $(K)$. In the following we show that the existence of a fixed point for a Kannan contraction in a orbitally complete generalized metric space is actually a consequence of Theorem 1.4.

In our proof we use the following lemma, which can immediately be proved by induction on $n$, without involving the triangle inequality:

Lemma 2.2. If $(X, d)$ is a generalized metric space and $T: X \rightarrow X$ is a mapping such that, for some $0<\beta<\frac{1}{2}$,

$$
d(T x, T y) \leq \beta[d(x, T x)+d(y, T y)] \forall x, y \in X
$$

then

$$
d\left(T^{n} x, T^{n+1} x\right) \leq\left(\frac{\beta}{1-\beta}\right)^{n} d(x, T x) \quad(n \in \mathbb{N})
$$

for every $x \in X$.

Proof. From

$$
d\left(T x, T^{2} x\right) \leq \beta\left[d(x, T x)+d\left(T x, T^{2} x\right)\right]
$$


it follows that

$$
d\left(T x, T^{2} x\right) \leq \frac{\beta}{1-\beta} d\left(T x, T^{2} x\right) .
$$

Next, from $(K), d\left(T^{n+1} x, T^{n+2} x\right) \leq \beta d\left(T^{n} x, T^{n+1} x\right)+\beta\left(T^{n+1} x, T^{n+2} x\right)$ so, from

$$
\left(T^{n} x, T^{n+1} x\right) \leq\left(\frac{\beta}{1-\beta}\right)^{n} d(x, T x)
$$

we obtain

$$
d\left(T^{n+1} x, T^{n+2} x\right) \leq \frac{\beta}{1-\beta} d\left(T^{n} x, T^{n+1} x\right) \leq\left(\frac{\beta}{1-\beta}\right)^{n+1} d(x, T x) .
$$

Let us now suppose, with the aim to reach to a contradiction, that $T$ has no fixed point.

We note that if $m, n, m \neq n$ are two positive integer numbers, then $T^{m} x \neq$ $T^{n} x \forall x \in X$, for if $T^{m} x=T^{n} x$ for some $x \in X$ then $y=T^{n} x$ is a fixed point for $T$. Indeed, from $T^{m} x=T^{n} x$ it follows $T^{m-n}\left(T^{n} x\right)=T^{n} x$, i.e. $T^{k} y=y$, where $k=m-n \geq 1$ and therefore

$$
d(y, T y)=d\left(T^{k} y, T^{k+1} y\right) \leq\left(\frac{\beta}{1-\beta}\right)^{k} d(y, T y)
$$

Since $0<\frac{\beta}{1-\beta}<1$, we obtain that $d(y, T y)=0$, that is, $y=T y$.

Define

Since

$$
\rho(x, y)= \begin{cases}d(x, T x)+d(y, T y), & x \neq y \\ 0, & x=y\end{cases}
$$

$$
\begin{gathered}
\rho(x, y)=d(x, T x)+d(y, T y) \\
\leq d(x, T x)+2 d(z, T z)+d(y, T y)=\rho(x, z)+\rho(z, y),
\end{gathered}
$$

for all $x, y \in X, x \neq y, \rho$ is a metric on $X$.

Also,

$$
\begin{gathered}
\rho(T x, T y)=d\left(T x, T^{2} x\right)+d\left(T y, T^{2} y\right) \\
\leq \beta\left[d(x, T x)+d\left(T x, T^{2} x\right)\right]+\beta\left[d(y, T y)+d\left(T y, T^{2} y\right)\right] \\
=\beta\left[d\left(T x, T^{2} x\right)+d\left(T y+T^{2} y\right)\right]=\beta \rho(x, y)+\beta \rho(T x, T y),
\end{gathered}
$$

that is,

$$
\rho(T x, T y) \leq q \rho(x, y) \forall x, y \in X,
$$

where $q=\frac{\beta}{1-\beta} \in(0,1)$.

We show that

$$
d\left(T^{n} x, T^{m} x\right) \leq 2 \rho\left(T^{n} x, T^{m} x\right) \quad(m \geq n) .
$$

This inequality is obvious if $m=n$. It is also immediate if $m=n+1$, because

$$
d\left(T^{n} x, T^{n+1} x\right) \leq d\left(T^{n} x, T^{n+1} x\right)+d\left(T^{n+1} x, T^{n+2} x\right)=\rho\left(T^{n} x, T^{n+1} x\right) .
$$

If $m>n+1$, then

$$
\begin{gathered}
d\left(T^{n} x, T^{m} x\right) \leq d\left(T^{n} x, T^{n+1} x\right)+d\left(T^{n+1} x, T^{m+1} x\right)+d\left(T^{m} x, T^{m+1} x\right) \\
=\left[d\left(T^{n} x, T^{n+1} x\right)+d\left(T^{m} x, T^{m+1} x\right)\right]+d\left(T^{n+1} x, T^{m+1} x\right)
\end{gathered}
$$




$$
\leq(1+\beta) \rho\left(T^{n} x, T^{m} x\right) \leq 2 \rho\left(T^{n} x, T^{m} x\right)
$$

(note that if $m>n+1$, then $T^{m} x, T^{m+1} x, T^{n} x, T^{n+1} x$ are four distinct points in $X)$.

Next, we prove that $(X, \rho)$ is $T$-orbitally complete. We know that there is $x \in X$ such that for every $d$-Cauchy sequence $\left\{x_{n}\right\}$ contained in $O(x, \infty)$ there exists $u \in X$ such that $d\left(x_{n}, u\right) \rightarrow 0$. Let $\left\{x_{n}\right\}$ be a $\rho$-Cauchy sequence contained in $O(x, \infty)$. From the just proven inequality it follows that $\left\{x_{n}\right\}$ is also $d$-Cauchy, so $d\left(u, x_{n}\right) \rightarrow 0$ for some $u \in X$. We may assume that $x_{n} \neq u$ for some $n$, for otherwise $\rho\left(x_{n}\right)$ converges to $u$ and we have nothing to prove. Then $u, x_{n}, T u, T x_{n}$ are four distinct points of $X$. For otherwise, $T^{k} x=T u$ or $T^{k} x=T u$ for some $k \in \mathbb{N}$, which would imply $\lim _{n \rightarrow \infty} T^{n} u=u$, and so, by letting $n \rightarrow \infty$ in $d\left(T^{n+1} u, T u\right) \leq \beta\left[d\left(T^{n} u, T^{n+1} u\right)+d(u, T u)\right] \quad(n \in \mathbb{N})$, we would obtain

$$
d(u, T u) \leq \beta d(u, T u) .
$$

Since $\beta<1, d(u, T u)$ must be 0 , that is, $u=T u$, contradicting the fact that $T$ is a fixed point free mapping.

Now, since $x_{n} \neq x_{n^{\prime}}$ for some $n^{\prime}>n$, we have

$$
\begin{gathered}
\rho\left(u, x_{n}\right)=d(u, T u)+d\left(x_{n}, T x_{n}\right) \\
\left.\leq\left[d\left(u, x_{n}\right)+d\left(x_{n}, T x_{n}\right)+d\left(T x_{n}, T u\right)\right]+d\left(x_{n}, T x_{n}\right)\right] \\
\leq d\left(u, x_{n}\right)+2 d\left(x_{n}, T x_{n}\right)+2 d\left(x_{n^{\prime}}, T x_{n^{\prime}}\right)+\beta \rho\left(x_{n}, u\right) \\
=d\left(u, x_{n}\right)+2 \rho\left(x_{n}, x_{n^{\prime}}\right)+\beta \rho\left(x_{n}, u\right) .
\end{gathered}
$$

It follows that

$$
(1-\beta) \rho\left(u, x_{n}\right) \leq d\left(u, x_{n}\right)+2 \rho\left(x_{n}, x_{n^{\prime}}\right),
$$

that is, $\rho\left(u, x_{n}\right) \rightarrow 0$.

Thus, $(X, \rho)$ is $T$-orbitally complete. From Theorem 1.4 it follows that $T$ has a fixed point, contradicting our assumption. This completes the proof.

\section{REFERENCES}

[1] M. Akram, A. Siddiqui, A fixed point theorem for A-contractions on a class of generalized metric spaces, Korean J. Math. Sciences 10 (2) (2003), 1-5. 1

[2] A. Azam, M. Arshad, Kannan fixed point theorem on generalized metric spaces, J. Nonlinear Sci. Appl. 1 (1) (2008), 45-48. 1

[3] A. Branciari, A fixed point theorem of Banach-Caccioppoli type on a class of generalized metric spaces, Publ. Math. Debrecen, 57 (1-2) (2000), 31-37. 1, 1.1, 1

[4] Lb. Cirić, A generalization of Banach's contraction principle, Proc. Amer. Math. Soc., 45(2) (1974), 267-273. 1.2

[5] P. Das, A fixed point theorem on a class of generalized metric spaces, Korean J. Math. Sc., 9 (1) (2002), 29-33. 1, 2

[6] P. Das, L.K. Dey, A fixed point theorem in a eneralized metric space, Soochow Journal of Mathematics 33 (1) (2007), 33-39. 1

[7] B.K. Lahiri, P. Das, Fixed point of a Ljubomir Ćirić's quasi-contraction mapping in a generalized metric space, Publ. Math. Debrecen, 61 (3-4) (2002), 589-594. 1 
[8] R. Kannan, Some results on fixed points, Bull. Cal. Math. Soc., 60 (1968),71-76. 1

[9] D.N. Sarknel, Banach's fixed point theorem implies Kannan's, Bull. Cal. Math. Soc., 91 (2) (1999), 143-144. 1

1 West University of Timişoara, Bv. V. Parvan 4, 300223, Timişoara, Romania. E-mail address: mihet@math.uvt.ro 